\title{
Non-spinal Causes of Back Pain: An "Undiagnosed” Diagnosis
} Shakti Goel (1)

Orthopaedic Spine Surgeon and Researcher, Indian Spinal Injuries Centre, Vasant Kunj, New Delhi, India Address for correspondence: Shakti Goel, Orthopaedic Spine Surgeon and Researcher, Indian Spinal Injuries Centre, Vasant Kunj, New Delhi - 110 070, India. E-mail: shaktiagoel@gmail.com / shaktigoel@jmrionline.com

\section{Abstract}

Low back pain is a common ailment affecting individuals all around the globe. Majority of disability-adjusted life years lost among the working population is due to low back pain. Although the majority of surgeons/ physicians keep only spinal causes in mind while treating such an ailment, a number of other causes exist for such a pathology. This brief communication aims to make the readers aware of such non-spinal causes of low back pain.

Keywords: Back pain, Fibromyalgia, Mood disorders, Nonspinal, Obesity, Piriformis syndrome

\section{Introduction}

Since the time Lord Krishna corrected the kyphotic deformity of a female, spine surgery has seen massive revolution. However, the myth of remaining on bed/complete bed rest without a definitive diagnosis has existed since long among traditional orthopedicians. This myth is not only prevalent among the patients but also various physicians/practitioners. Many times, a patient with back pain is advised to stay on the bed and take medicines. With the advancements in spine and spine research, various causes of back pain have been found. Although a majority of spine surgeons/physicians focus on spinal causes of back pain, a few of the non-spinal causes must be kept in mind to make a definitive diagnosis before treatment. This helps the patient to achieve a satisfactory treatment. ${ }^{[1]}$

\section{Non-spinal Causes of Back Pain}

Thenon-spinalcausesofbackpaincould beenlisted under the following headings [Table 1]:

1. Visceral causes of back pain

2. Bursitis

3. Piriformis syndromes

4. Spasticity

5. Fibromyalgia

6. Degenerative joint disease (DJD)

7. Posture
8. Limb length discrepancy

9. Obesity

10. Mood disorders

11. Secondary gain.

\section{Visceral Causes of Back Pain}

Sometimes, back pain is the single presenting symptoms of some of the medical conditions. It is important that the clinician identifies the cause and provides the necessary treatment. Management of such a disorder with simple analgesics may prove to be fatal/Examination of the abdomen with palpation of the visceral organs is a necessary step of diagnosis. Some of the differential diagnosis for such an ailment could be prostatitis, pyelonephritis, urinary tract infection, aortic aneurysm, acute pancreatitis, duodenal ulcers, cholecystitis, nephrolithiasis, and visceral cancers.

\section{Bursitis}

Trochanteris Bursitis and ischiogluteal bursitis are types of pelvic pain that is sometimes misdiagnosed as herniated disc or sciatica from the lumbosacral region. This is most commonly encountered in the elderly population. The symptoms of trochanteric bursitis areapain in the hip region with tenderness and increase in pain with activity. With ischiogluteal bursitis, the pain is localized deep in the center of the buttock which is aggravated by sitting or

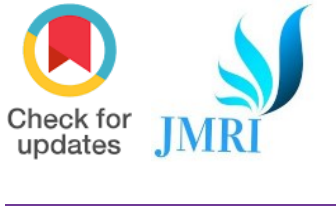

How to cite this article: Goel S. Non-spinal Causes of Back Pain: An "Undiagnosed" Diagnosis. Journal of Medical Research and Innovation. 2019;3(2):e000172.

Doi: 10.32892/jmri.172

Publication history: Received: 11-01-2019

Accepted: 13-02-2019

Published: 17-02-2019

Editor: Dr. Varshil Mehta

Copyright: Goel S. This is an open access article distributed under the terms of the Creative Commons Attribution License CC-BY4.0., which permits unrestricted use, distribution, and reproduction in any medium, provided the original author and source are credited.

Funding: NIL

Conflict of Interest: NIL

MK Medkrux 


\section{Goel: Non-spinal Causes of Back Pain}

Table 1: Non-spinal causes of back pain

\begin{tabular}{|c|c|c|}
\hline Causes & Subtypes & Examples \\
\hline Visceral causes & & $\begin{array}{l}\text { Dissecting aortic aneurysm, urinary tract infection, pyelonephritis, } \\
\text { prostatitis, pelvic inflammatory disease, endometriosis, ovulation, } \\
\text { pregnancy, ectopic pregnancy, acute pancreatitis, duodenal ulcer, } \\
\text { cholecystitis, nephrolithiasis, visceral cancers. }\end{array}$ \\
\hline \multicolumn{3}{|l|}{ Piriformis syndrome } \\
\hline \multirow[t]{2}{*}{ Bursitis } & Trochanteric bursitis & \\
\hline & Ischiogluteal bursitis & \\
\hline \multicolumn{3}{|l|}{ Fibromyalgia } \\
\hline Spasticity & & $\begin{array}{l}\text { Cerebral palsy, traumatic brain injury, stroke, multiple sclerosis, spinal } \\
\text { cord injury }\end{array}$ \\
\hline DJD of hip & & Osteoarthritis of the hip (primary or secondary) \\
\hline Limb length discrepancy & & $\begin{array}{l}\text { Previous injury or fracture to limb, bony diseases, inflammation, } \\
\text { osteoarthritis, neurologic condition }\end{array}$ \\
\hline \multirow[t]{2}{*}{ Posture } & Lumbar hyperlordosis & \\
\hline & Thoracic hyperkyphosis & \\
\hline \multicolumn{3}{|l|}{ Obesity } \\
\hline \multicolumn{3}{|l|}{ Mood disorders } \\
\hline Secondary gain & & \\
\hline
\end{tabular}

walking and accompanied by radicular pain which is not relieved by rest. Treatment includes rest, anti-inflammatory medications, physical therapy, cortisone injections, or sometimes bursectomy. ${ }^{[2]}$

\section{Piriformis Syndrome}

It is sciatic symptoms which do not originate from the lumbosacral plexus or disc herniation butby pressure from the piriformis muscle on the sciatic nerve. ${ }^{[3]}$ The pain increases on activity such as prolongessitting and walking. The muscle originated from the anterolateral aspect of the sacroiliac region, transverses the sciatic nerve and inserts into the Greater Trochanter of the Femur. It has the function of abducting the lateral rotator of Femur and is innervated by S1 and S2. The Sciatic nerve is found between the two bellies of Piriformis. ${ }^{[4]}$ Any irritation or inflammation over the muscle compresses the sciatic nerve and precipitates the symptoms of sciatica. Straight leg raising (SLR) test could help in differentiating piriformis syndrome from Lumbar Disc Herniation. SLRis usually negative in Piriformis syndrome unless the leg of the patient is flexed, adducted, and internally rotated.

\section{Spasticity}

Spasticity is usually found in patients with chronic neurologicalillnesssuchasstroke, spinal cordinjury, and multiple sclerosis. It is clinically manifested as a hypertonic state of muscles with clonus and involuntary movements. Back pain is a cardinal feature of spaticity. ${ }^{[5]}$

\section{Fibromyalgia}

It is a chronic pain syndrome which is characterized by widespread musculoskeletal pain, fatigue and heightened tenderness to tactile pressure, general fatigue, and sleep disturbance. The most common sites of pain include "tender points" of neck, back, shoulders, bony pelvis, and hands. Pain is described as a deep ache, sometimes shooting and burning.

\section{Degenerative Joint Disease (DJD)}

DJD of the hip is most often caused by arthritis. Such a condition causes ipsilateral groin and medial joint pain. Sometimes the pain may radiate to knee on the same side, creating the confusion if the pain is from hip or knee or lumbar radiculopathy. The pain from the hip can be easily distinguished from the lumbar radiculopathy as the latter does not affect the range of motion of the joint. Furthermore, various tests of osteonecrosis of femur head/ osteoarthritis hip, etc., shall be positive in cases of DJD of thehip. 


\section{Goel: Non-spinal Causes of Back Pain}

\section{Posture}

The position of the body in both sitting and standing position has a considerable effect on back pain. Lumbar hyperlordosis in standing and slouched position on sitting can affect the health and functioning of the muscles of the abdomen and lower back. When daily activities require prolonged sitting or standing, this leads to various ailments of the back. ${ }^{[3]}$

\section{Limb Length Discrepancy}

There are a variety of causes for limb length discrepancy including previous injury or fracture to the leg, bony diseases, inflammation, and osteoarthritis and neurologic conditions. The correlation between patients with a clinically significant leg length discrepancy and the incidence of low back pain is controversial. The discrepancy in limbs could lead to pelvic obliquity which changes the coronal balance of sacrum leading to segmental scoliosis and increased risk of low back pain. ${ }^{[3]}$ Such a discrepancy may also lead to gait abnormalities in patients.

\section{Obesity}

Overweight is a contributing factor to back pain and a significant cause of seeking medical care. It can contribute to the symptoms of osteoporosis, osteoarthritis, degenerative spine disease, and spondylolisthesis. The extra weight usually translates extra strain to the lower back. ${ }^{[6]}$

\section{Mood Disorders}

In patients with chronic and disabling pain syndromes such as fibromyalgia and mood disorders are frequently encountered along with back pain. Patients with diagnosed anxiety and depression report higher incidences and greater severity of pain in addition to increased disability and dysfunction due to pain compared to patients without depression and anxiety. ${ }^{[7]}$ Treatment of both pain and mood disorder is challenging but can beaccompanied by a comprehensive plan including cognitive behavioral therapy, relaxation techniques, hypnosis, exercises, antidepressants, and mood stabilizers.

\section{Secondary Gain}

Secondary gain is an external psychological motivator that may drive a patient to report certain symptoms. If a patient's pain or illness allows them tomiss work orgain extrasympathyand attention, these would be examples of secondary gain. These need to be carefully identified by the physician.

\section{Conclusion}

These are common causes which need to be kept in mind before treating a patient with back pain. Sometimes the illness is much beyond the spinal disorder and needs to be treated meticulously. A comprehensive multi-disciplinary approach is thus warranted.

\section{References}

1. Srivastava N, Goel S. A study of patient satisfaction level in inpatient spine department of a tertiary care multispecialty hospital. J Med Res Innov 2019;3:e000147. DOI: 10.15419/jmri.147. [Full-Text]

2. Dougherty CD, Dougherty JJ. Evaluating hip pathology in trochantric pain syndrome. JMusculoskel Med 2008;9:428-36. [Full-Text]

3. Cailliet R. Low Back Pain Syndrome. $4^{\text {th }}$ ed. Philadelphia, PA: FA Davis; 1988.

4. Saladin K. Anatomy and Physiology: The Unity of Foam and Function. $1^{\text {st }}$ ed. New York: Mc-Graw Hill WCB; 1998.

5. Greenberg MS, Arredondo N. Handbook of Neurosurgery. $6^{\text {th }}$ ed. New York: Thieme Medical Publishers; 2006.

6. Shiri R, Karppinen J. The association between obesity and low back pain: Ameta-analysis. Am J Epidemiol 2010;171:135-54. DOI: 10.1093/aje/kwp356. [FullText] [PubMed]

7. Means-Christensen AJ, Roy-Byrne PP, Sherbourne CD, Craske MG, Stein MB. Relationships among pain, anxiety, and depression in primary care. Depress Anxiety 2008;25:593-600. DOI: 10.1002/da.20342. [Full-Text] [PubMed]. 